UDC 316.7

LBC 60.524

\title{
SOCIOCULTURAL FOUNDATIONS OF EMBEDDING EXAMPLES OF DEVIANT BEHAVIOR IN THE PROCESS OF REGULATING SOCIAL INTERACTIONS OF THE YOUTH
}

\author{
Oleg V. Sorokin \\ Institute of Socio-Political Research - Branch of the Federal Center of Theoretical and Applied Sociology \\ of the Russian Academy of Sciences, Moscow, Russian Federation
}

\begin{abstract}
The article analyzes the social and cultural foundations in modern society, which stimulate the embedding of examples of deviant behavior in the process of regulating social interactions in the youth environment. The theoretical and methodological analysis of the main provisions of the structural-functional school (Durkheim, Merton) is presented, the problems of functional integration of cultural elements (Sorokin), the contradictions between culture and social relations (Lapin), the interaction of cultural and social in the process of social development (Ahiezer). Special attention was paid to the correlation of social and cultural tools for regulating individual behavior (Alexander), and the consistency of social and cultural in society (Kravchenko). The author's analysis allowed to determine the main theoretical contradictions of the social mechanism of transformations of social institutions (Zaslavskaya), describe the role of macro-institutions in society (Dimans, Levicheva), and identify the impact of social uncertainty (Chuprov) and social deformations (Kudryavtsev) on society. Conclusions are made about the influence of socio-cultural conditions on the formation of deviant behavior patterns in conditions of uncertainty and the discontinuity of social interactions among young people. Social and cultural grounds determine the nature and direction of regulation of social interactions in society and the predominance of patterns of acceptable, normative or deviating from generally accepted norms of behavior in the mechanism of regulation. The mismatch of cultural and social grounds, as one of the key causes of this phenomenon, is studied from the positions of classical and modern sociological concepts. This discrepancy leads to an increase in illegal practices among young people. The above-mentioned processes of mismatch are accompanied by: dysfunction of macroinstitutions; deformation of the mechanism of normative regulation; reinterpretation of normative patterns in the social reality of young people; giving them a new, deviant meaning. The consequence of these processes is the formation of hybrid forms of regulation of social interactions in the youth environment, when normative patterns coexist with patterns of deviant behavior in the social reality of youth.
\end{abstract}

Key words: culture, social interactions, sociocultural regulation, deviant behavior, youth, patterns of deviant behavior, youth consciousness.

УДК 316.7

ББК 60.524

\section{СОЦИОКУЛЬТУРНЫЕ ОСНОВАНИЯ ВСТРАИВАНИЯ ОБРАЗЦОВ ДЕВИАНТНОГО ПОВЕДЕНИЯ В ПРОЦЕСС РЕГУЛЯЦИИ СОЦИАЛЬНЫХ ВЗАИМОДЕЙСТВИЙ В МОЛОДЕЖНОЙ СРЕДЕ}

Олег Владимирович Сорокин

Институт социально-политических исследований ФНИСЦ РАН, г. Москва, Российская Федерация

Аннотация. В статье анализируются социальные и культурные основания в современном обществе, которые стимулируют встраивание образцов девиантного поведения в процесс регуляции социальных 
взаимодействий в молодежной среде. Представлен теоретико-методологический анализ основных положений структурно-функциональной школы (Дюркгейм, Мертон), рассмотрены проблемы функциональной интеграции элементов культуры (Сорокин), противоречия между культурой и социальными отношениями (Лапин), взаимодействия культурных и социальных оснований в процессе социального развития (Ахиезер). Особое внимание уделено соотношению социальных и культурных инструментов регуляции поведения индивида (Александер), согласованности социального и культурного в обществе (Кравченко). Проведенный анализ позволил определить основные теоретические противоречия обоснования социального механизма трансформаций социальных институтов (Заславская), описать роль макроинститутов в обществе (Диманс, Левичева), выявить влияние на социум социальной неопределенности (Чупров) и социальных деформаций (Кудрявцев). Сделаны выводы о влиянии социокультурных условий на формирование образцов девиантного поведения в условиях неопределенности, разорванности социальных взаимодействий в молодежной среде. Социальные и культурные основания определяют характер и направленность регуляции социальных взаимодействий в обществе и преобладание в механизме регуляции образцов допустимого, нормативного или отклоняющегося от общепринятых норм поведения. Рассогласование культурных и социальных оснований, как одна из ключевых причин данного явления, изучается с позиций классических и современных социологических концепций. Отмечается, что данное рассогласование приводит к росту неправовых практик в молодежной среде. Вышеназванные процессы рассогласования сопровождаются: дисфункцией макроинститутов; деформацией механизма нормативной регуляции; переосмыслением нормативных образцов в социальной реальности молодежи; наделением их новым, отклоняющимся значением. Следствием данных процессов становится складывание гибридных форм регуляции социальных взаимодействий в молодежной среде, когда нормативные образцы соседствуют с образцами девиантного поведения в социальной реальности молодежи.

Ключевые слова: культура, социальные взаимодействия, социокультурная регуляция, девиантное поведение, молодежь, образцы девиантного поведения, молодежное сознание.

В философской и социологической литературе вопросы, связанные с изучением проблемы регуляции социальных взаимодействий, тесно переплетаются с проблемой выделения социальных и культурных оснований общественных процессов. Попытка поиска социокультурных оснований отклоняющегося поведения в социологии была предпринята впервые на серьезной методологической базе в рамках структурно-функциональной школы, предвестником появления которой был Э. Дюркгейм [Durkheim 1964]. Разделение труда, и последующее за ним «функциональное разнообразие влечет за собой моральное, которое ничто не может предупредить: одно неизбежно возрастает вместе с другим» [Дюркгейм 1996, 370]. В разделении труда Э. Дюркгейм видел источник ослабления коллективной солидарности, то есть состояние общества, когда индивид больше не удерживается социальной группой, поскольку разрушается традиционная социальная организация. Изменение социальной организации приводит к изменению коллективного сознания группы, поскольку ослабление коллективных чувств уменьшает ее внутреннюю интеграцию. У Э. Дюркгейма интеграция в группе и в обществе - это результат влияния на коллектив- ное сознание права и нравственности: «человек моральное существо только потому, что живет он в обществе, ибо нравственность состоит в том, чтобы быть солидарным с группой, и она изменяется вместе с этой солидарностью» [Дюркгейм 1996, 407]. Моральные регуляторы поведения человека - это производные от социальной жизни, следовательно, способ социальной организации определяет характер морали. Человек вне общества становится безнравственным существом. Эволюция общества, по мнению, Э. Дюркгейма, ослабляет взаимосвязь индивида с «его семьей, с родной землей, с завещанными прошлым традициями, с коллективными обычаями группы» [Дюркгейм 1996, 408]. Состояние зависимости от общества сдерживает в нем эгоистичное начало и сохраняет индивидуальную нравственность, поскольку в этом случае воспроизводится коллективный тип личности. Моральные регуляторы в условиях ранней индустриализации ослабевают в силу того, что утрачиваются традиции, которые поддерживали коллективное моральное сознание. Таким образом, Э. Дюркгейм одним из первых сформулировал тезис о том, что встраивание образцов девиантного поведения в процесс регуляции социальных взаимодействий в 
раннем индустриальном обществе обусловлено влиянием социальных факторов, которые являются основополагающими по отношению к факторам культурным.

Р. Мертон, вслед за Э. Дюркгеймом, представил целостную концепцию социокультурных оснований регуляции социальных взаимодействий. В своих работах Р. Мертон последовательно развивал идею о том, что преобладание образцов отклоняющегося поведения в сознании маргинальных групп с ограниченными возможностями для социального продвижения вызваны их культурной мотивацией. Причину рассогласования культурной мотивации определенных групп и социальной структуры Р. Мертон видел в разных целях. Культурные цели и институционализированные нормы придают форму существующим практикам [Мертон 2006, 246]. Если индивид испытывает удовлетворение от достижения культурных целей, то это свидетельствует о равновесии в обществе культурных и социальных структур. Расхождение между культурными предписаниями и социальными способами их достижения, по мнению Р. Мертона, является причиной отклоняющегося поведения в обществе. Культурная шкала ценностей, принятая в обществе, определяет престиж, статус человека. По мнению мыслителя, господствующая в культуре шкала ценностей благодаря родителям, школе, референтным группам воспроизводится в конкретных социальных группах и социальных классах. В этом случае механизмы общественного презрения не действуют в отношении тех, кто согласно общепринятой шкале ценностей, достиг успеха даже неправовым, возможно, криминальным путем, поскольку в дальнейшем многие уважаемые люди в обществе посчитают за честь дружить с подобными людьми. Для многих представителей низших социальных групп достижение материального успеха в развитом индустриальном обществе затруднено в силу ограниченных ресурсов, поэтому единственным реальным способом приумножения материального благополучия становится вовлечение в девиантные формы поведения.

В рамках структурно-функциональной школы социальная организация и культурные нормы выступают как внешние факторы ре- гуляции поведения индивида. Человек приходит в систему координат, которая уже задолго до него сложилась как система взаимосвязанных социальных институтов и механизмов регуляции поведения. Данные механизмы направляют поведение индивида в конструктивное русло. Встраивание образцов отклоняющегося поведения в процесс регуляции социальных взаимодействий при таком подходе является результатом рассогласования культурных и социальных структур. В классической и современной социологии было предложено множество других подходов, объясняющих причины данного рассогласования.

П.А. Сорокин обратился к проблеме функциональной интеграции элементов культуры. Элементы культуры объединяются в конфигурации с целью обеспечения функционального единства внутри социального организма. Синтез культурных элементов, согласно П.А.Сорокину, отвечает также за выполнение общественных функций социальными институтами. При этом механический перенос некоторых культурных элементов из их естественной среды в другое общество приводит к деструктивным последствиям, так институты общества демократической правовой системы не могут эффективно функционировать в обществе с социально-кастовым строем [Sorokin 1962]. Исследователь отмечает «логикосмысловые» культурные комплексы, которые намного прочнее причинно-функциональных комплексов, поскольку выступают высшими формами интеграции. Культурные комплексы, в форме социальных институтов скрывают в себе определенные смыслы, которые наделяют данные комплексы и институты типичными формами и значимыми образцами [Sorokin 1962]. Анализ социальных процессов посредством поиска закономерностей причинно-функциональных и логико-смысловых взаимосвязей элементов культуры отражает преобладание социальных и культурных факторов в процессе регуляции поведения социальных субъектов по мнению мыслителя.

Схожий взгляд на данную проблему предлагает современный отечественный мыслитель Н.И. Лапин. Социальные и культурные основания, согласно Н.И. Лапину, лежат в основе человеческой деятельности [Лапин 2000, 32]. При этом культура отвечает за создание 
инновационных алгоритмов деятельности в материальной и духовной сферах, а социальность - за формирование отношений между субъектами в процессе возникающих новых алгоритмов деятельности. Баланс социальных и культурных оснований осуществляется через совокупность социетальных процессов. Так, в современном обществе, в условиях возрастающих потребностей индивида, открывается пространство для целерациональных инноваций [Лапин 2000, 33]. Рост инновационной активности человека ставит под угрозу прежний социальный порядок и систему социальной устойчивости, однако, социальные и культурные основания на социетальном уровне поддерживают целостность общества. Вместе с тем, в условиях трансформации, по мнению Н.И. Лапина нарастают противоречия между культурой и социальными отношениями. Подобная ситуация оборачивается ценностно-нормативным расколом в обществе, отражая «патологическое состояние социальной системы» [Беляева, Лапин (ред.) 1994, 50]. К примеру, социальные отношения могут не соответствовать динамике культурных изменений. Так, реформы в культуре оборачиваются ростом недовольства в обществе. Возможны и обратные процессы, когда насаждаемые сверху социальные институты не согласуются с общепринятыми культурными ценностями.

Аспекты взаимодействия культурных и социальных оснований в процессе социального развития подробно изучал отечественный мыслитель А.С. Ахиезер. Исследователь обратился к проблеме реализации культурных замыслов, в т.ч. нравственных и моральных программ, в социальном действии, например, когда культурные институты перерастают в социальные институты [Ахиезер 1997, 21]. Именно культурные факторы определяются социальные изменения по мнению мыслителя. При этом движущую силу развития общества исследователь видит в противоречиях, которые возникают между культурой и социальными отношениями. А.С. Ахиезер одним из первых в отечественной философии пытался изучить общее между ментальностью, как отражением культурного, и институциональным, как совокупностью общественных практик. Результатом взаимодействия культуры и социального, согласно А.С. Ахиезеру, стано- вятся конкретные формы общественной жизни, которые доказали свою состоятельность и эффективность в условиях новых вызовов для развития общества. В обществе складываются культурные программы, несущие в себе инновационные алгоритмы деятельности, которые вступают в противоречие с и исторически сложившимися программами, а значит, складываются новые социальные отношения, которые вступают в противоречие со сложившимися социальными отношениями. Рассогласование культурного и социального может стать причиной дальнейшего развития общества, если в нем возобладают формы общественной жизни, воплотившие в себя инновационные практики, это рассогласование может стать причиной дезорганизации и разрушения, если новые образцы отклоняющегося поведения вступят в противоречие с действующей системой общественных отношений [Ахиезер 1997, 22]. «Если культура создает основы для сохранения через деятельность людей исторически сложившихся социальных отношений, то она сохраняет и социальную основу своего существования. Если культура этого обеспечить не может, то гибнет ее массовая социальная база, гибнут социальные институты, которые ее сохраняют, защищают от различных опасностей», - отмечает исследователь [Ахиезер 1997, 55]. Социально-воспроизводственная деятельность человека направлена на преодоление социальной энтропии, когда складывающиеся противоречия между культурными основаниями и социальными основаниями удерживаются в определенных приемлемых значениях. Нравственные идеалы, как основания культуры, как идеалы человека, человеческого поведения, социальных отношений, государственности, нацеливают общество на свое воспроизводство, на разрешение социокультурных противоречий [Ахиезер 1997, 60].

Дж. Александер в вопросе соотношения социальных и культурных оснований регуляции поведения индивида отводит культуре первостепенную роль, а точнее «автономии культуры» [Alexander 2003]. По мнению мыслителя, социология слишком много времени потратила на описание человеческой деятельности как инструментальной, которой управляют «моральные структуры: «сакральное-благое» и 
«профаное-злое» [Александер 2013, 65]. Культурные смыслы, с точки зрения Дж. Александера воздействуют на формирование социальной жизни и идентичностей. Появлением такого подхода в вопросе соотношения культурных и социальных оснований социология обязана структуралистской герменевтике, в которой смыслы рассматриваются как производные от знаковой системы, именно это определяет степень автономии культуры по отношению к социальной детерминации, а это означает, что культура - это объективная структура, как и любой материальный социальный факт [Александер 2013, 89]. Поэтому для понимания особенностей социальной структуры конкретного общества и причин встраивания образцов девиантного поведения в процесс регуляции социальных взаимодействий в данном обществе необходима реконструкция его культурной структуры. Данные культурные структуры создаются лидерами мнений, средствами массовой информации, которые комбинируют знаки и символы, направляя внимание масс на определенные смысловые дискурсы. Так, Дж. Александер объясняет действие механизма «нормализации ненормального» в современном обществе, когда образцы девиантного поведения начинают соседствовать с образцами социально-одобряемого поведения в массовом сознании.

С.А. Кравченко в вопросе регуляции социального поведения индивида отводит первостепенную роль согласованности социального и культурного в обществе, отмечая, что нарушение данной согласованности приводит к разрыву преемственности ценностных и нормативных оснований общества [Кравченко (ред.) 2017, 80]. «Текучая» современность делает невозможным процесс воспроизводства общества, а, следовательно, и исторической преемственности культурных образцов. Результатом этого становится утрата обществом всеобщей значимости нравственных универсалий, недолговечность ценностно-нормативных образцов и встраивание в процесс регуляции социальных взаимодействий образцов девиантного поведения.

Таким образом, социальные и культурные основания определяют характер и направленность регуляции социальных взаимодействий в обществе и преобладание в механизме регуляции образцов допустимого, норма- тивного или отклоняющегося от общепринятых норм поведения. Носителями данных форм поведения в обществе чаще остальных становятся молодежные группы, которые заметнее активнее вовлекаются в инновационные социальные практики. В свою очередь социокультурные основания закладывают противоречия и пути их разрешения в процессе зарождения новых культурных алгоритмов деятельности и отражения их в разных типах молодежного сознания.

В современной отечественной социологии были предприняты попытки поиска причин данных противоречий. Так, Т.И. Заславская отмечает, что постсоветские реформы в российском обществе были направлены на создание эффективной институциональной системы, которая позволила бы России сохранить достойное место в современном мире. К элементам данной институциональной системы исследователь относит: эффективное правовое государство, многообразные формы легитимной и защищенной собственности, гражданское общество, демократические права и свободы [Заславская, Калугина (ред.) 2003, 153]. Таким образом, Т.И. Заславская выделяет три базовых, системообразующих макроинститута общества: экономический, политический и правовой. Схожую точку зрения на роль макроинститутов в обществе отстаивают в своих исследованиях С.Л. Диманс и В.Ф. Левичева, которые полагают что данные институты формируют социальную реальность и задают стандарты социального поведения людей [Диманс, Левичева 2018, 5]. В условиях, когда усиливаются противоречия между формально-правовыми базовыми институтами и культурными составляющими, возникают ситуации институционализации неправовых практик. Выделяя системообразующие макроинституты Т.И. Заславская, по сути, рассматривает ядро жизнедеятельности общества как социальной системы. В основе данного ядра находятся социальные практики, которые в процесс воспроизводства социальной системы институционализируются макроинститутами и отражаются в институционально одобряемых формах коллективного поведения. Однако когда действующие макроинституты перестают отвечать потребностям и интересам большинства населения, актуа- 
лизируются неправовые практики. Особенно данные процессы характеры для молодежи, поскольку в основе данных неправовых практик заложены культурные основания, которые отражают идеалы, цели развития общества, отвечающие интересам молодых людей, которые вступают во взрослую жизнь и интегрируются в общественные процессы. При этом макроинституты утрачивают свою функциональность, как не отвечающие интересам больших социальных групп. Дисфункциональность макроинститутов компенсируется усилением влияния неправовых практик в молодежной среде.

Так, дисфункция правового социального института у Т.И. Заславской проявляется в нарушении свобод и прав граждан. В условиях дисфункции правового института значительное число молодых граждан обращаются к неправовым способам адаптации к новым условиям, по сути, к неправовым практикам. Рост в обществе неправовых видов практик при массовой поддержке со стороны населения приводит к преобразованию данных практик в новые социальные формы. Основная причина данной тенденции, по мнению Т.И. Заславской, кроется в массовой правовой беспомощности, когда многие граждане в сложившихся условиях распространения неправовых практик не способны, что-либо противопоставить конструктивное. В таких условиях институционализируется право сильного при беззащитности слабого. Получив массовое распространение в обществе неправовые практики постепенно встраиваются в новые общественные институты, «обуславливая их «мутацию» [Заславская, Калугина (ред.) 2003, 158].

При этом функциональность социальных институтов отражает их способность эффективно регулировать массовые социальные взаимодействия с помощью образцов нормативного поведения, то есть определять цели деятельности института, рационально организовывать внутренние и внешние связи, способность поддерживать доверие к институту и его результатам со стороны большинства членов общества, способность удовлетворять потребности граждан общества, поддерживать и исполнять сами социальные нормы. Помимо образцов социально-одобряемого поведения, которые производятся и поддерживаются социальными институтами в обществе складывает множество неформальных норм, которые охраняются и контролируются в большей степени общественным мнением и моральными оценками. Эффективность формальных норм зависит от легитимности социальных институтов, что выражается в доверии к данным институтам и производимых ими нормам со стороны большинства граждан. В свою очередь, эффективность неформальных норм зависит, с одной стороны, от уровня правосознания граждан и их общественной активности.

В основе макроинститутов - ядра жизнедеятельности социальной системы, лежат социальные практики, которые отличаются наибольшей социальной значимостью, массовостью и устойчивостью. Данные социальные практики проходят фильтрацию и отбор социальными институтами, конечная цель этих процедур - установление воспроизводимого и разделяемого большинством нормативного порядка. Однако существуют огромные вариации социальных практик, которые не охвачены вниманием макроинститутов. Оставаясь на периферии социальной системы данные практики, отражая всю совокупность неформальных отношений в обществе, превращаются, зачастую, в неправовые практики, т.е. практики которые существуют помимо «официально провозглашенных правил игры». Данные практики заметнее всего присутствуют в молодежной среде, в силу особенностей включения представителей данной возрастной группы в различных субкультурные пространства.

Существование неформальных, в частности, неправовых практик у молодежных групп и их институционализация в форме неформальных институтов, например, молодежной моды, во многом обусловлена спецификой культурного пространства, в котором разворачивается регулирование социальных процессов в молодежной среде. В культурном пространстве молодежных субкультур могут быть представлены образцы отклоняющегося поведения, которые для носителей данной субкультуры по своей значимости могут стоять выше формально институционализированных социальных практик.

В устойчиво развивающемся обществе неправовые практики, существующие в молодежной среде, не инкорпорируются в формаль- 
ные социальные институты, поскольку находятся на периферии и поддерживаются малыми общностями. В условиях переходного общества, быстрых социальных перемен, ситуация видоизменяется. Неформальные практики молодежи, которые несут в себе инновационный потенциал, получают импульс признания со стороны большинства граждан, которые нуждаются в переменах в обществе. Поэтому данные практики начинают активно встраиваться в институциональную матрицу регулирования общественной жизни.

Регулярное расхождение массовых социальных практик с действующими административно-правовыми нормами обусловлено, как правило, социальными процессами, которые характеризуются динамичностью, хаотичностью и бессистемностью. По сути, это свидетельствует о глубоком социетальном кризисе, в котором оказалось конкретное общество. В таких условиях, даже при усиливающемся формальном контроле, ослабляется контроль неформальный, поскольку все больше смыслы административно-правовых норм отрываются от смыслов тех социальных практик, которые укоренились или укореняются в обществе. Усиливающаяся дисфункциональность социальных институтов становится системным ответом на подобный бессистемный вызов. Дисфункция базовых институтов общества оборачивается деформацией всех привычных социальных структур и нравственных устоев, что свидетельствует о складывании нового типа реальности, в котором социальная неопределенность становится доминирующим фактором для молодежи [Чупров, Зубок, Романович 2019, 23 ]. В условиях социальной неопределенности утрачивается способность молодых людей адекватно рефлексировать по вопросам управления и планирования своей жизни.

В.Н. Кудрявцев, изучая проблему социальных деформаций, содержательно раскрыл аспект, связанный с разрушением нормативной системы в условиях социально-экономического кризиса. Деформация социальных норм с точки зрения данного исследователя является закономерным результатом деформации смежных систем - социальных институтов и ценностных ориентаций людей [Кудрявцев 2017, 51]. Так понимание нравственных ценностей варьируется в разных соци- альных слоях, нациях и возрастных группах. В условиях социально-экономических перемен система ценностей конкретных индивидов, социальных групп перестает совпадать с их реальными условиями жизни, так возникает «двойная мораль» [Кудрявцев 2017, 52]. В этом случае «противоречивые нормы используются одним и тем же лицом (социальной группой) для разных целей в одних и тех же сходных ситуациях». Социальные нормы начинают восприниматься большинством граждан как неэффективные и несправедливые. Именно в такие периоды в обществе усиливается «теневое нормотворчество», когда разные социальные группы создают систему норм, противоречащую общепринятой системе норм. При этом новые нормы наряду с общепринятыми наделяются статусом регулятивных, то есть получают средства воздействия на поведения человека в форме санкций и морального принуждения. Рост популярности в обществе теневых, криминальных практик в этом случае объясняется складыванием «извращенной» морали, так как преступный мир берет из общепринятой морали и религии самое сильное и эффективное: неминуемость кары, «внутренний голос» совести и слепую веру [Кудрявцев 2017, 57]. При этом сам процесс создания подобных норм - это уже есть опасное общественное явление, это своеобразный вид социального отклонения.

Примером, иллюстрирующим подобные расхождения, являются драматичные события, которые наблюдались в российском обществе в конце XX - начале XXI века. Попытка механического переноса ценностно-нормативных комплексов западной демократии на российскую почву в 90-е гг. ХХ в. стала причиной ускорения деформации прежних макроинститутов и роста недоверия к насаждаемых сверху новым ценностно-нормативным регуляторам. Активизация в рассматриваемый период неправовых практик, особенно в молодежной среде, отчуждение большей ее части от политической сферы, сферы труда и брачно-семейных отношений стало результатом субъективного трактования смыслов административно-правовых норм либерального типа, когда, инициативность, сознательность и ответственность за принимаемые решения стали подменяться вседозволенностью, распущенностью и полным 
отрицанием данных норм. Многие транслируемые в тот период практики не находили согласование с культурными практиками, сложившимся в российском обществе, поскольку представлявшие их социальные институты искусственно вживлялись в институциональное ядро.

Помимо вышеописанных негативных последствий главным следствием стало стремительное распространение в молодежной среде противозаконных, криминальных практик. В социально-экономических условиях, складывающихся в современном российском обществе в период распространения пандемии коронавирусной инфекции, сохраняются риски вовлечения молодежи, особенно подростков, в неправовые, криминальные практики. Поэтому встраивание образцов девиантного поведения в процесс регуляции социальных взаимодействий в социальной реальности молодежи остается одной из актуальных проблем современного российского общества.

\section{СПИСОК ЛИТЕРАТУРЫ}

Александер 2013 - Александер Дж. Смыслы социальной жизни: Культурсоциология. М.: Праксис, 2013.

Ахиезер 1997 - Ахиезер А.С. Россия: критика исторического опыта: (социокультурная динамика России). Т. 1. От прошлого к будущему. Новосибирск: Сиб. хронограф, 1997.

Беляева, Лапин (ред.) 1994 - Беляева Л.А., Лапин Н.И. (ред.). Кризисный социум. Наше общество в трех измерениях. М.: ИФРАН, 1994.

Диманс, Левичева 2018 - Диманс С.Л., Левичева В.Ф. Люди и нормы: институты VS неформальные практики. М.: Ключ-С, 2018.

Дюркгейм 1996 - Дюркгейм Э. О разделении общественного труда. М.: Канон, 1996.

Заславская, Калугина (ред.) 2003 - Заславская Т.И., Калугина 3.И. (ред.). Россия, которую мы обретаем. Новосибирск: Наука, 2003.

Кравченко (ред.) 2017 - Кравченко С.А. (ред.). «Нормальная аномия» в России и современном мире: коллектив. моногр. М.: МГИМОУниверситет, 2017.

Кудрявцев 2017 - Кудрявцеев В.Н. Социальные деформации (причины, механизмы и пути преодоления). М.: Норма: Инфра-М, 2017.

Лапин 2000 - Лапин Н.И. Социокультурная трансформация России: либерализация versus традиционализация // Журнал социологии и социальной антропологии. 2000. Т. 3, № 3. С. $32-39$.
Мертон 2006 - Мертон Р. Социальная теория и социальная структура. М.: АСТ: Хранитель, 2006.

Чупров, Зубок, Романович 2019 - Чупров В.И., Зубок Ю.А., Романович Н.А. Доверие в саморегуляции изменяющейся социальной реальности: монография. М.: Норма, 2019.

Alexander 2003 - Alexander J.C. The Meanings of Social Life. A Cultural Sociology. N. Y.: Oxford University Press, 2003.

Durkheim 1964 -Durkheim E. The Division of Labor in Society. N. Y.: Freepress; L.: Collier Macmillan, 1964.

Sorokin 1962 - Sorokin P. Social and Cultural Dynamics. Vol. 1. N.Y.: The Bedminster Press, 1962.

\section{REFERENCES}

Alexander J.C., 2013. The Meanings of Social Life: A Cultural Sociology. Moscow, Praksis Publ.

Ahiezer A.S., 1997. Russia: Critique of Historical Experience: (Sociocultural Dynamics of Russia). Vol. 1. From the Past to the Future. Novosibirsk, Sib. khronograf Publ.

Belyaeva L.A., Lapin N.I. (eds.), 1994. Crisis Society. Our Society in Three Dimensions. Moscow, Institute of philosophy of the Russian Academy of Sciences.

Dimans S.L., Levicheva V.F., 2018. People and Norms: Institutes VS Informal Practices. Moscow, Key-C Publ.

Durkheim E., 1996. The Division of Labor in Society. Moscow, Kanon Publ.

Zaslavskaya T.I., Kalugina Z.I. (eds.), 2003. Russia, Which We Find. Novosibirsk, Nauka Publ.

Kravchenko S.A. (ed.), 2017. "Normal Anomie" in Russia and the Modern World: A Collective Monograph. Moscow, MGIMO-University.

Kudryavtsev V.N., 2017. Social Deformations (Causes, Mechanisms and Ways of Overcoming). Moscow, Norma Publ.: Infra-M Publ.

Lapin N.I., 2000. Sociocultural Transformation of Rossia: Liberalization vs Traditionalization. Journal of Sociology and Social Anthropology, vol. 3, no. 3, pp. 32-39.

Merton R., 2006. Social Theory and Social Structure. Moscow, AST Publ., Khranitel Publ.

Chuprov V.I., Zubok Yu.A., Romanovich N.A., 2019. Trust in Self-Regulation of Changing Social Reality. Moscow, Norma Publ.

Alexander J.C., 2003. The Meanings of Social Life. A Cultural Sociology. New York, Oxford University Press.

Durkheim E., 1964. The Division of Labor in Society. New York, Free press; London, Collier Macmillan.

Sorokin P., 1962. Social and Cultural Dynamics. Vol. 1. New York, The Bedminster Press. 


\section{СОЦИОЛОГИЯ И СОЦИАЛЬНЫЕ ТЕХНОЛОГИИ}

\section{Information About the Author}

Oleg V. Sorokin, Candidate of Sciences (Sociology), Senior Researcher, Institute of SocioPolitical Research - Branch of the Federal Center of Theoretical and Applied Sociology of the Russian Academy of Sciences, Fotievoy St, 6, Bld. 1, 119333 Moscow, Russian Federation, ov.sorokin@gmail.com, https://orcid.org/0000-0003-2597-9465

\section{Информация об авторе}

Олег Владимирович Сорокин, кандидат социологических наук, старший научный сотрудник, Институт социально-политических исследований ФНИСЦ РАН, ул. Фотиевой, 6, корп. 1, 119333 г. Москва, Российская Федерация, ov.sorokin@gmail.com, https://orcid.org/0000-0003-2597-9465 